\title{
Effect of Microwave and Pressure Cooking on Stability of Vitamin C in Some Selected Vegetables
}

\author{
Shobham, Karukonda Raju, Mudhavath Mounica and M.K. Sukumaran* \\ Department of Biochemistry, Bhavan's Vivekananda College, Sainikpuri, \\ Secunderabad, Telangana, India \\ *Corresponding author
}

\section{A B S T R A C T}

\begin{tabular}{|l|}
\hline Key w ord s \\
Vitamin C, \\
Microwave \\
cooking, Pressure \\
cooking, Vegetables \\
\hline Article Info \\
\hline Accepted: \\
23 July 2017 \\
Available Online: \\
10 September 2017 \\
\hline
\end{tabular}

This investigation was carried out to evaluate and compare the effect of microwave and pressure cooking methods on the contents of vitamin $\mathrm{C}$ in selected vegetables. Total vitamin $\mathrm{C}$ contents of raw vegetables ranged between 3.55 to $91.27 \mathrm{mg} / 100 \mathrm{~g}$ respectively. Microwave and pressure cooking for 2 to $3 \mathrm{~min}$ resulted in considerable loss of vitamin C. However, the loss was higher in the case of pressure cooking when compared to microwave cooking. Therefore, microwave cooking can be preferred over pressure cooking.

\section{Introduction}

Human body has evolved to process cooked foods more efficiently. This may be mainly due to the fact that raw foods are much harder to digest, taking longer time and burning more calories. Therefore, cooking plays a major role to minimize energy consumption and simple digesting of food. Some of these cooking methods have been shown to affect nutrient and health-promoting compounds like vitamin $\mathrm{C}$, carotenoids, polyphenols, and glucosinolates in broccoli (Cieslik et al., 2007; Lin and Chang, 2005; Sikora et al., 2008 and Vallejo et al., 200). Micronutrients (e.g., vitamins) are an essential component of human nutrition. Some of these micronutrients are sensitive to processing and cooking, hence a significant amount may be lost during these processes (Pearson, 1973; Les4kova et al., 2003 and Ball, 2006). Loss of micronutrient in cooked food may involve factors like; temperature and duration for which the food is cooked (Pearson, 1973) and method of cooking. It has been observed that water soluble vitamins tend to be more sensitive and unstable than fat soluble ones (Somogyi and Muller., 1989).

Vitamin $\mathrm{C}$ is water soluble and it is thought to be most susceptible vitamin among the other vitamins (Ottaway, 1993). Therefore, at times it is considered as an index of nutrient quality (Erentuk et al., 2005) (e.g., losses of other less sensitive micronutrients like folates). Keeping in view the sensitivity of vitamin $\mathrm{C}$ 
during the process of cooking, the present study was undertaken to evaluate the loss of vitamin $\mathrm{C}$ content in selected vegetables as affected by different cooking (microwave and pressure cooking) methods.

\section{Materials and Methods}

Vegetables (cabbage, bitter gourd, green chilli, cauliflower, brinjal, spinach, potato and carrot) used in the study were purchased from the local market in Hyderabad city.

\section{Cooking procedure}

Two different cooking methods were employed in our studies;

\section{Microwave cooking}

$100 \mathrm{~g}$ of the vegetable was placed in a glass dish and $10 \mathrm{~mL}$ of distilled water was added to it. The dish was then covered with cooking bag, having holes and cooked in a LG Microwave oven on a high power level for 2 to $3 \mathrm{~min}$. After cooking, the vegetable was drained off and cooled rapidly on plenty of ice. All the vegetables were similarly treated.

\section{Pressure cooking}

$100 \mathrm{~g}$ of the vegetable (in $50 \mathrm{~mL}$ of distilled water) was pressure cooked (Prestige $3 \mathrm{~L}$ Pressure Cooker) for 2 to $3 \mathrm{~min}$ at $121^{\circ} \mathrm{C}$ and pressure of 15 ' $\mathrm{lb}$ '. Immediately the vegetable was drained off and cooled rapidly on plenty of ice.

All the vegetables were similarly treated.

Determination of vitamin $C$ in raw, microwave and pressure cooked vegetables

Vitamin $\mathrm{C}$ content in the raw, microwave and pressure cooked vegetables were determined by the protocol outlined by Deekshika et al.,
(2015) and Rao and Deshpande, 2006). Vitamin $\mathrm{C}$ content in the raw vegetables was considered as $100 \%$ and percentage loss of vitamin $\mathrm{C}$ in microwave and pressure cooked vegetables were calculated.

\section{Results and Discussion}

\section{Determination of vitamin $\mathbf{C}$ content in raw vegetables}

The vitamin $\mathrm{C}$ content among the different vegetables varied significantly (Table 1). In their raw state, vitamin $\mathrm{C}$ content was found to be highest in cabbage $(91.27 \mathrm{mg} / 100 \mathrm{~g})$ and lowest in carrot $(3.55 \mathrm{mg} / 100 \mathrm{~g})$ (Table 1 and Figure 1) among the different vegetables.

The vitamin C contents $(\mathrm{mg} / 100 \mathrm{~g})$ of the investigated vegetables were in the order of cabbage (91.27) > bitter gourd (76.63) > green chilly $(74.18)>$ cauliflower $(67.08)>$ brinjal $(26.12)>\operatorname{spinach}(17.74)>$ potato (11.61) > carrot (3.55) (Table 1 and Figure 1).

\section{Effect of microwave and pressure cooking on vitamin $C$ in some vegetables}

Both microwave and pressure cooking resulted in the loss of vitamin $\mathrm{C}$ content among the different vegetables (Table 2).

As evident from the data presented in table 2, pressure cooking resulted in a higher loss of vitamin $\mathrm{C}$ as compared to microwave cooking,

Percentage loss of vitamin $\mathrm{C}$ content in microwave and pressure cooked vegetables were as follows; cabbage (9.89 and 49.47), bitter gourd (19.20 and 55.80), green chilly (11.31 and 49.57), cauliflower (20.68 and 46.15), brinjal (19.75 and 54.06), spinach (30.89 and 70.91), potato (27.73 and 72.18) and carrot (27.32 and 67.32) respectively (figures 2 to 9 ). 
Fig.1 Determination of vitamin $\mathrm{C}$ content in raw vegetables

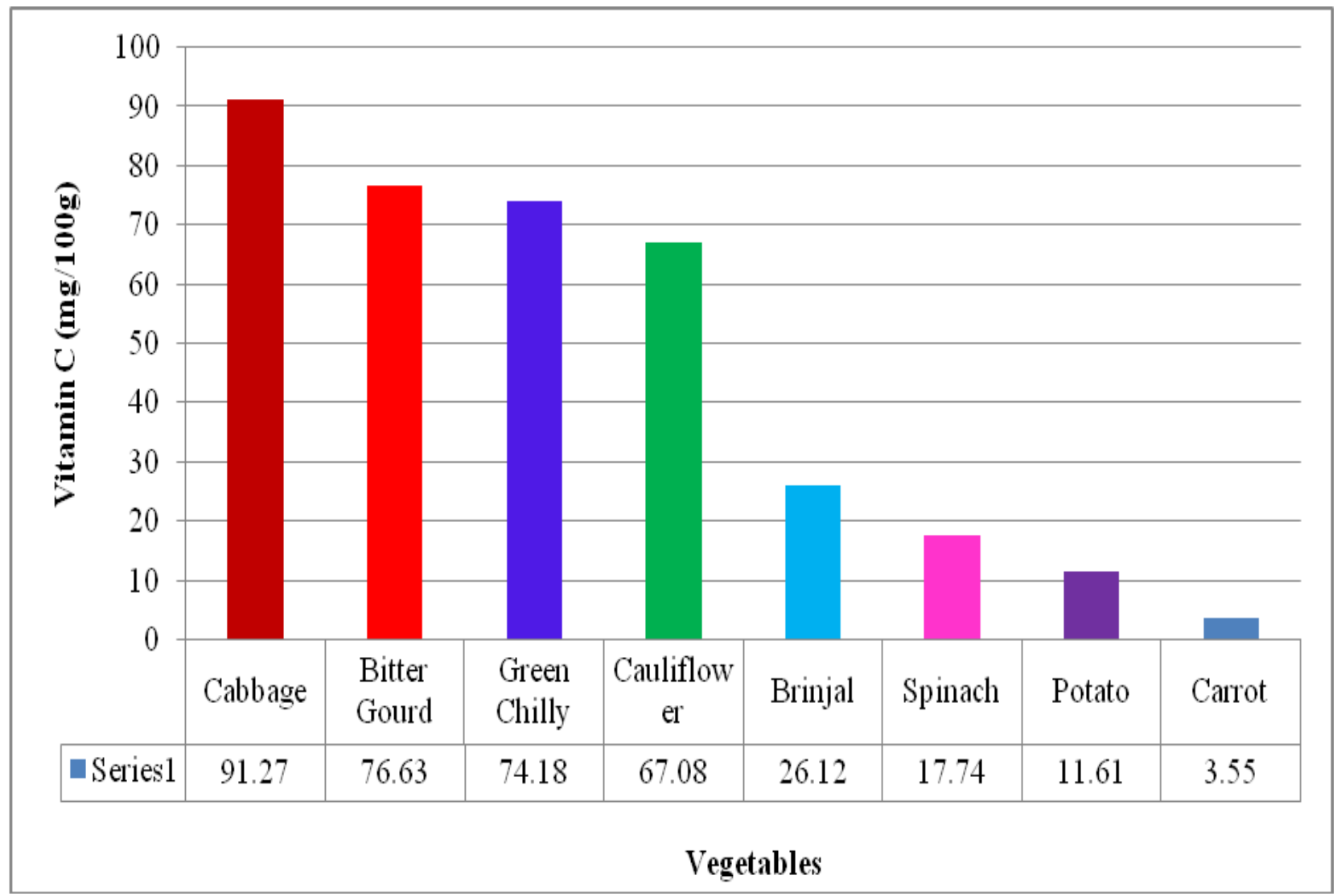

Loss of Vitamin C (mg/100g) content during the process of microwave and pressure cooking

Fig.2

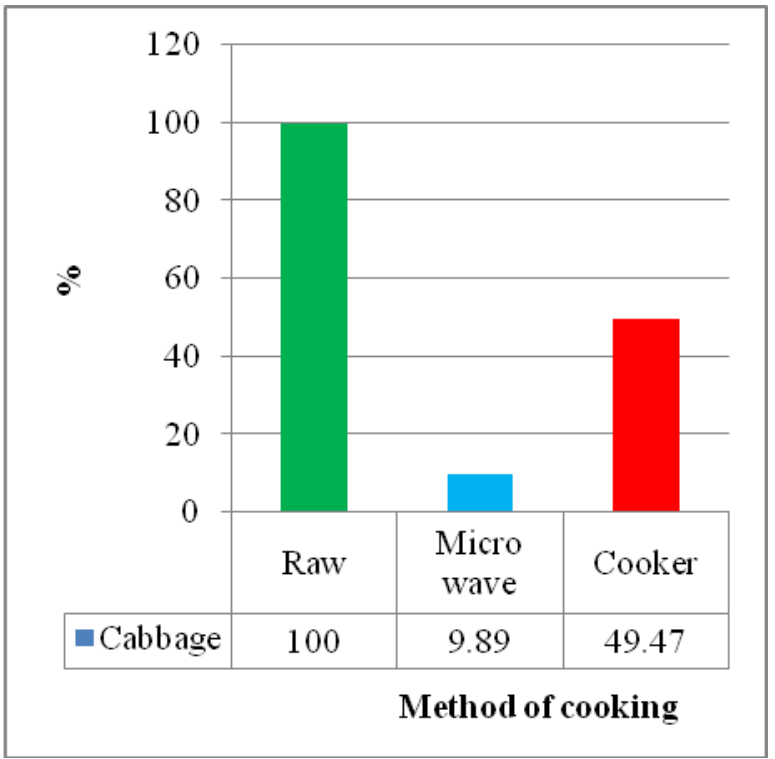

Fig.3

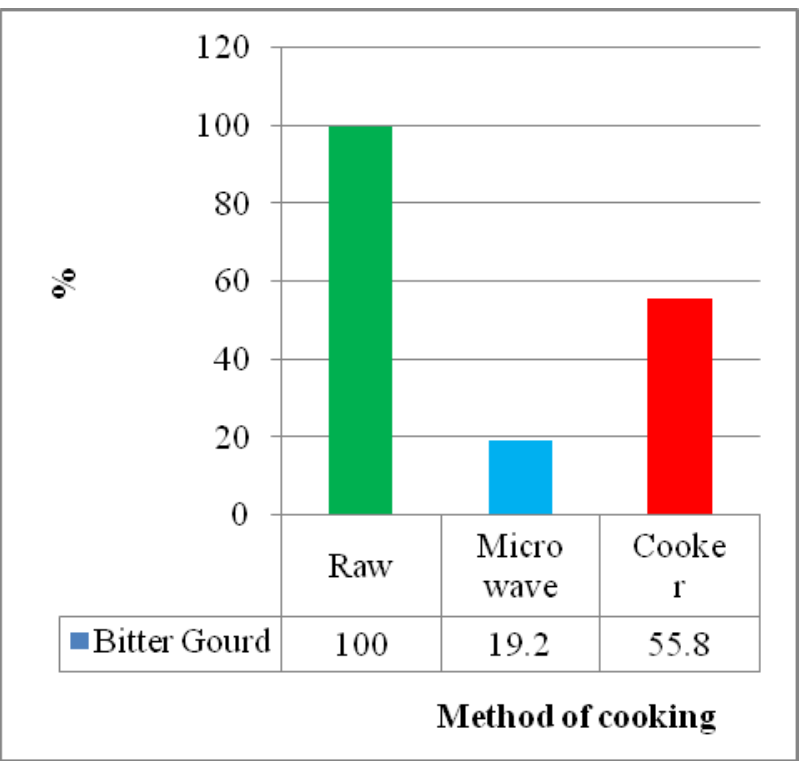


Fig.4

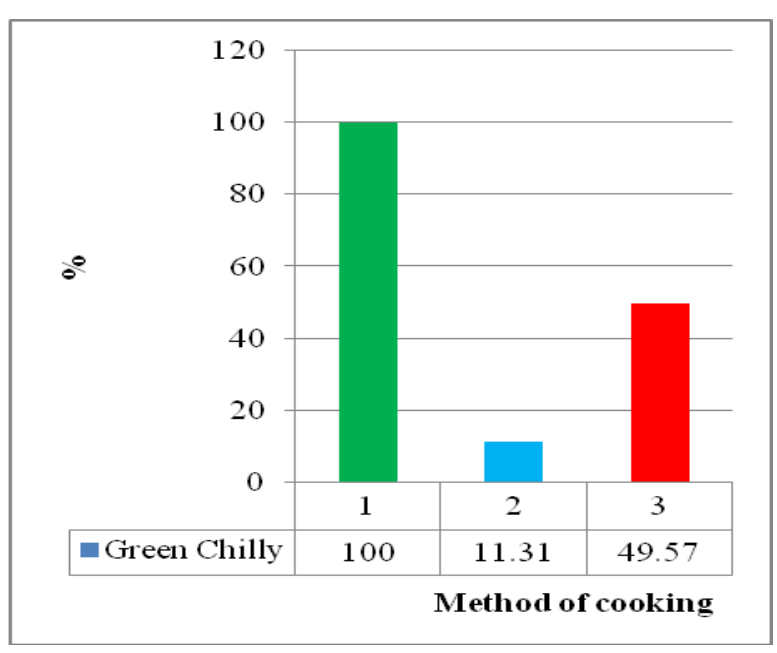

Fig.6

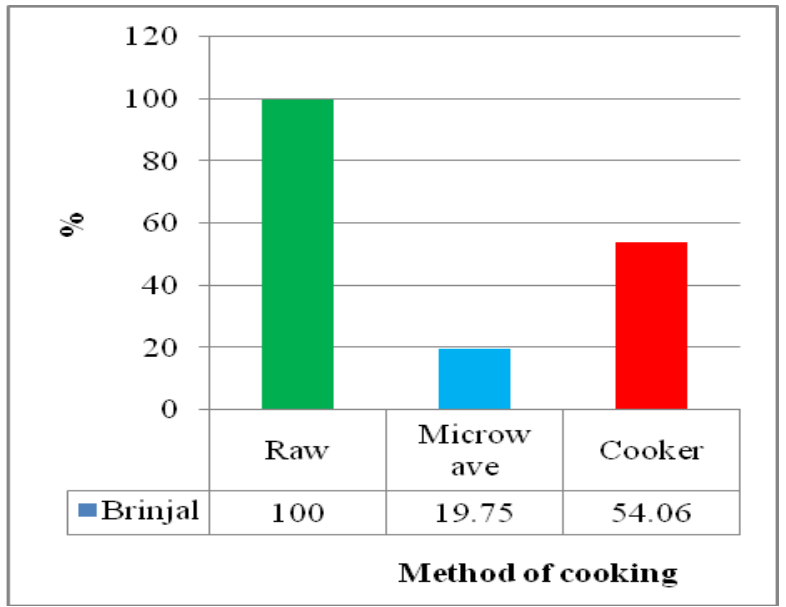

Fig.8

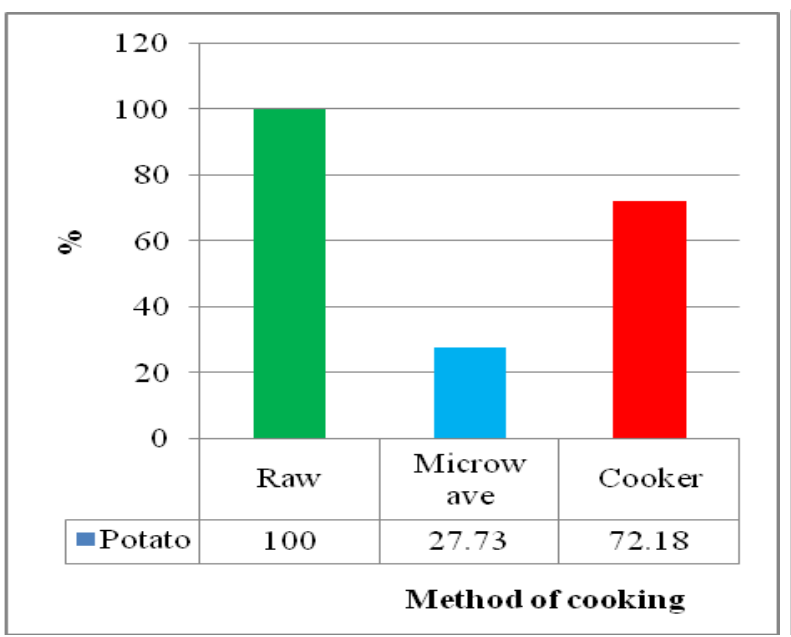

Fig.5

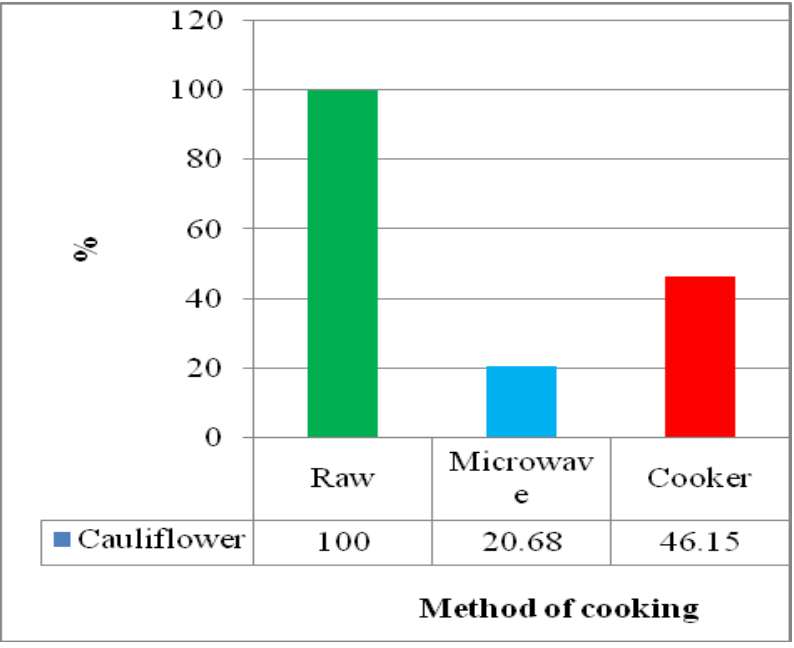

Fig.7

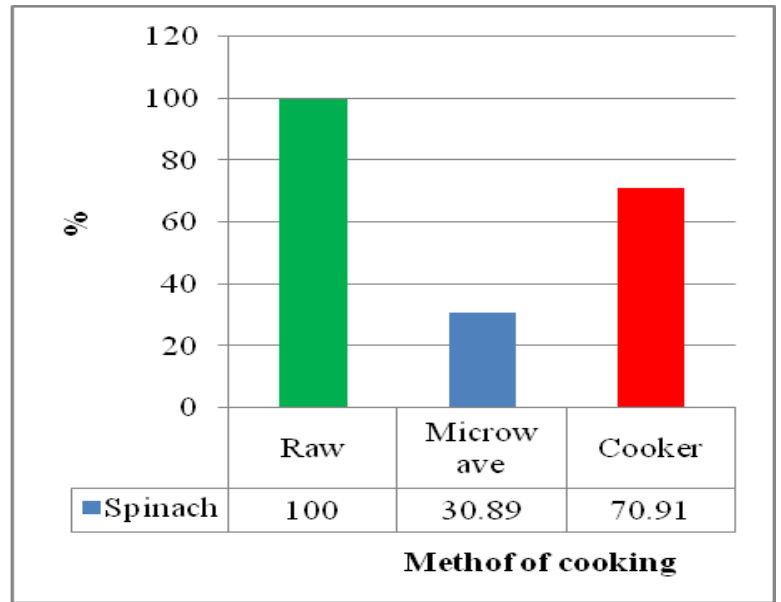

Fig.9

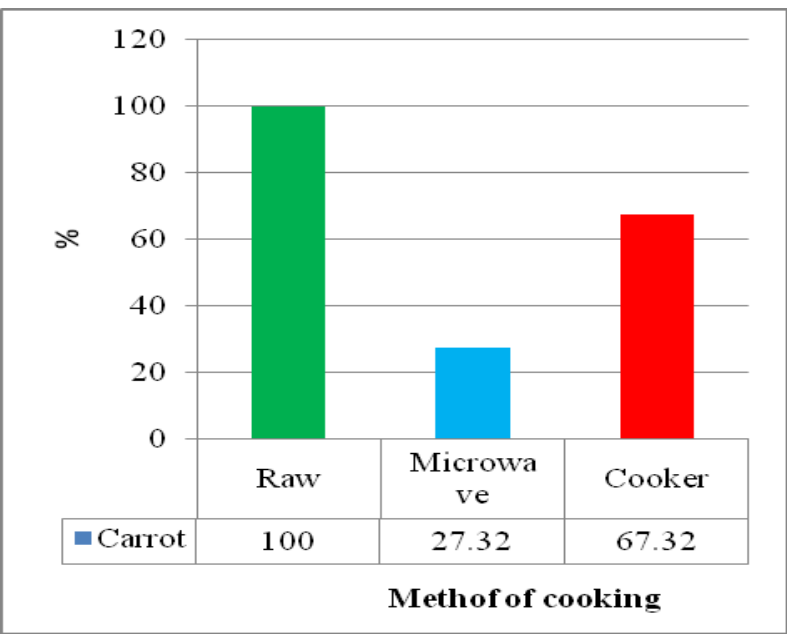


Table.1 Determination of vitamin C content in raw vegetables

\begin{tabular}{|c|l|c|}
\hline S. No & Vegetable & Raw \\
\hline 1 & Cabbage & 91.27 \\
\hline 2 & Bitter Gourd & 76.63 \\
\hline 3 & Green Chilly & 74.18 \\
\hline 4 & Cauliflower & 67.08 \\
\hline 5 & Brinjal & 26.12 \\
\hline 6 & Spinach & 17.74 \\
\hline 7 & Potato & 11.61 \\
\hline 8. & Carrot & 3.55 \\
\hline
\end{tabular}

Table.2 Loss of vitamin C (mg/100g) content during the process of microwave and pressure cooking

\begin{tabular}{|c|l|c|c|c|}
\hline \multirow{2}{*}{ S. No } & Vegetables & \multicolumn{3}{|c|}{ Method of Cooking } \\
\cline { 3 - 5 } & & Raw & $\begin{array}{l}\text { Microwave } \\
\text { Loss }\end{array}$ & $\begin{array}{l}\text { Pressure } \\
(\%) \text { Loss }\end{array}$ \\
\hline 1 & Cabbage & 100 & 9.89 & 49.47 \\
\hline 2 & Bitter Gourd & 100 & 19.20 & 55.80 \\
\hline 3 & Green Chilly & 100 & 11.31 & 49.57 \\
\hline 4 & Cauliflower & 100 & 20.68 & 46.15 \\
\hline 5 & Brinjal & 100 & 19.75 & 54.06 \\
\hline 6 & Spinach & 100 & 30.89 & 70.91 \\
\hline 7 & Potato & 100 & 27.73 & 72.18 \\
\hline 8 & Carrot & 100 & 27.32 & 67.32 \\
\hline \multicolumn{2}{|l|}{ Minimum \% loss } & & $\mathbf{9 . 8 9}$ & $\mathbf{4 6 . 1 5}$ \\
\hline \multicolumn{2}{|l|}{ Avaximum \% loss } & & $\mathbf{3 0 . 8 9}$ & $\mathbf{7 2 . 1 8}$ \\
\hline \multicolumn{2}{|l|}{ \%verage $\%$ loss } & & $\mathbf{2 0 . 8 5}$ & $\mathbf{5 8 . 1 8}$ \\
\hline
\end{tabular}

Vallejo et al., in 2002 examined the effect of under and reduced pressure and microwave cooking on the ascorbic acid content of broccoli and suggested that there was a $40 \%$ loss in ascorbic acid content of broccoli that were cooked in microwave (Vallejo et al., 2002).

Khatoon and Prakash compared the effect of under pressure and microwave cooking on ascorbic content and concluded that there was a loss of $29-62 \%$ that was higher than the effect of pressure cooking (Khatoon and Prakash, 2006).
Studies by Yahyaei et al., in 2013, indicated that the ascorbic acid content of vegetables that were cooked for $10 \mathrm{~min}$ by conventional cooking preserves higher concentrations of ascorbic acid as compared to $10 \mathrm{~min}$ of pressure or microwave cooking. He also reported that the higher ascorbic acid concentration was preserved when $20 \mathrm{~min}$ of pressure cooking was applied at the same time, highest losses were observed in the carrot that were cooked for $20 \mathrm{~min}$ in microwave. The losses that accounted for $45.4 \%$ of the ascorbic acid originally present.

Boiling had a greater effect on vitamin $\mathrm{C}$ losses compared with microwaving, 
especially boiling for $6 \mathrm{~min}$. Boiling for $6 \mathrm{~min}$ caused a $64.45 \%$ decrease in broccoli, $70.74 \%$ in white cabbage and $66.82 \%$ in cauliflower (Shams El-Din et al., 2013).

India is the home of diverse cultures, languages, food habits. This diversity is evident in prevailing cooking methods in the different regions of our country. Cooking methods generally employed are boiling, steaming, pressure cooking, microwave cooking, frying (stir and deep frying) and baking, etc. Some of these cooking methods may deplete the essential nutrients that may be required for a healthy life. This work is being conducted to identify a cooking method that would cause minimal loss of the essential nutrients. Minimum, maximum and average loss of vitamin $\mathrm{C}$ content in microwave cooked vegetables was found out to be 9.89 , 30.89 and $20.85 \mathrm{mg} / 100 \mathrm{~g}$ and that in pressure cooked vegetables was found out to be 46.15 , 72.18 and $58.18 \mathrm{mg} / 100 \mathrm{~g}$ as compared to raw vegetables (Table 2). Though our studies indicate that there is a considerable loss of vitamin $\mathrm{C}$ in both microwave and pressure cooked vegetables the extent of loss was more in pressure cooked vegetables.

\section{Conflict of interest statement}

Author declares that there is no conflict of interest.

\section{Acknowledgment}

Authors are thankful to Management and Principal Prof. Y. Ashok, Bhavan's Vivekananda College for providing necessary facilities and constant encouragement.

\section{References}

Ball, G., 2006. Vitamins in Foods, Analysis, Bioavailability and Stability. CRC Press.
Cieslik, E., Leszczynska, T., FilipiakFlorkiewicz, A., Sikora, E., Pisulewski, P.M., 2007. Effects of some technological processes on glucosinolate contents in cruciferous vegetables. Food Chem., 105(3):976981 . [doi:10.1016/j. foodchem.2007.04.047].

Deekshika, B., Praveena Lakshmi, B., Hemanth Singuluri and. Sukumaran, M.K., 2015. Estimation of ascorbic acid content in fruits and vegetables from Hyderabad, India - A theoretical assessment of Vitamin $\mathrm{C}$ activity Int.J.Curr.Microbiol.App.Sci, 4(1): 9699.

Erentuk, S., Gualaboglu M.S. and S. Gultekin., 2005. The effects of cutting and drying medium on the vitamin $\mathrm{C}$ content of rosehip during drying. Journal of Food Engineering 68, 513518.

Khatoon, N., and Prakash, J. 2006. Nutrient retention in microwave cooked germinated legumes. Journal of Food Chemistry. 115-121.

Les4kova, E., Kova', J., Ikova', E., Kos4icka', M., Porubska', J. and Holc4Q'kova, K. 2003. Vitamin losses: Retention during heat treatment and continual changes expressed by mathematical models, Journal of Food Composition and Analysis, 252-276.

Lin, C.H., Chang, C.Y., 2005. Textural change and antioxidant properties of broccoli under different cooking treatments. Food Chem., 90(1-2):9-15. [doi:10.1016/j.foodchem.2004. 02.053].

Ottaway, P. B., 1993. The Technology of Vitamins in Food. Published by Blackie Academic and Professional, an important of Chapman and Hall.

Pearson, D., 1973. Laboratory Techniques in Food Analysis. Fric, First Published. 
Rao, B., and Deshpande, V., 2006. Experimental biochemistry. Tunbridge Wells, Kent: Anshan.

Shams El-Din, M.H.A., Madiha M. AbdelKader, Makhlouf, S.K., and Ola S.S. Mohamed., 2013. Effect of Some Cooking Methods on Natural Antioxidants and Their Activities in Some Brassica Vegetables, World Applied Sciences Journal 26 (6): 697703.

Sikora, E., Cieslik, E., Leszczynska, T., Filipiak-Florkiewicz, A., Pisulewski, P.M., 2008. The antioxidant activity of selected cruciferous vegetables subjected to aquathermal processing. Food Chem., 107(1):55-59. [doi:10.1016/j. foodchem.2007.07.023].
Somogyi, J. C., and Muller, H. R. 1989. Nutritional Impact of Food Processing. Published by The Group of European Nutritions.

Vallejo, F., Tomas-Barberan, F.A., GarciaViguera, C., 2002. Glucosinolates and vitamin $\mathrm{C}$ content in edible parts of broccoli florets after domestic cooking. Eur. Food Res. Technol., 215 (4):310316. [doi:10.1007/s00217-002-0560-8]. Yahyaei, M., Ghavami, A., Gharachorloo, M., Larijani, K., Mazhari, S. Z., 2013. The Effect of Different Methods of Heat Treatments on the Retention of Ascorbic Acid in Carrot and Corn, J. FBT, IAU, 3, 23-28.

\section{How to cite this article:}

Shobham, Karukonda Raju, Mudhavath Mounica and Sukumaran, M.K. 2017. Effect of Microwave and Pressure Cooking on Stability of Vitamin C in Some Selected Vegetables. Int.J.Curr.Microbiol.App.Sci. 6(9): 2391-2397. doi: https://doi.org/10.20546/ijcmas.2017.609.293 